THE UNIVERSITY OF MICHIGAN WILLOW RUN LABORATORIESReport of Project MICHIGAN

THE MAGNITUDE OF THE PULFRICH STEREOPHENOMENON AS A FUNCTION OF TARGET VELOCITY Alfred Lit

Vision Research Laboratories The University of Michigan

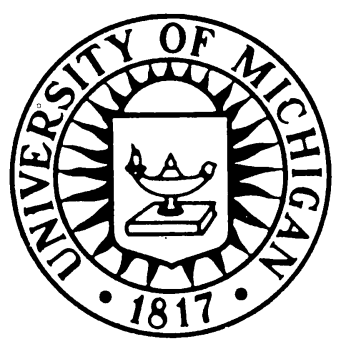

January 1959

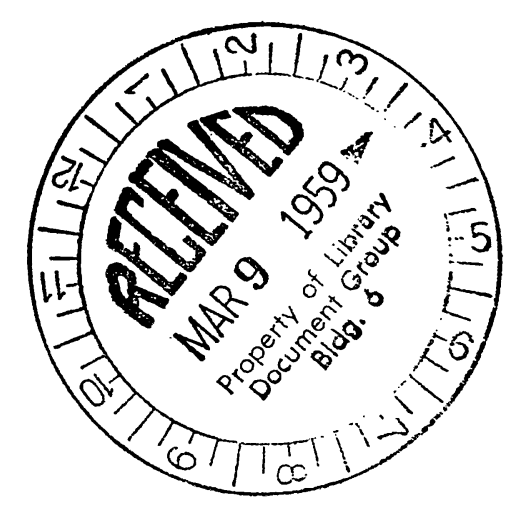


After this document has served its purpose, it may be destroyed in accordance with provisions of the Industrial Security Manual. Please do not return it to the Willow Run Laboratories of The University of Michigan. 


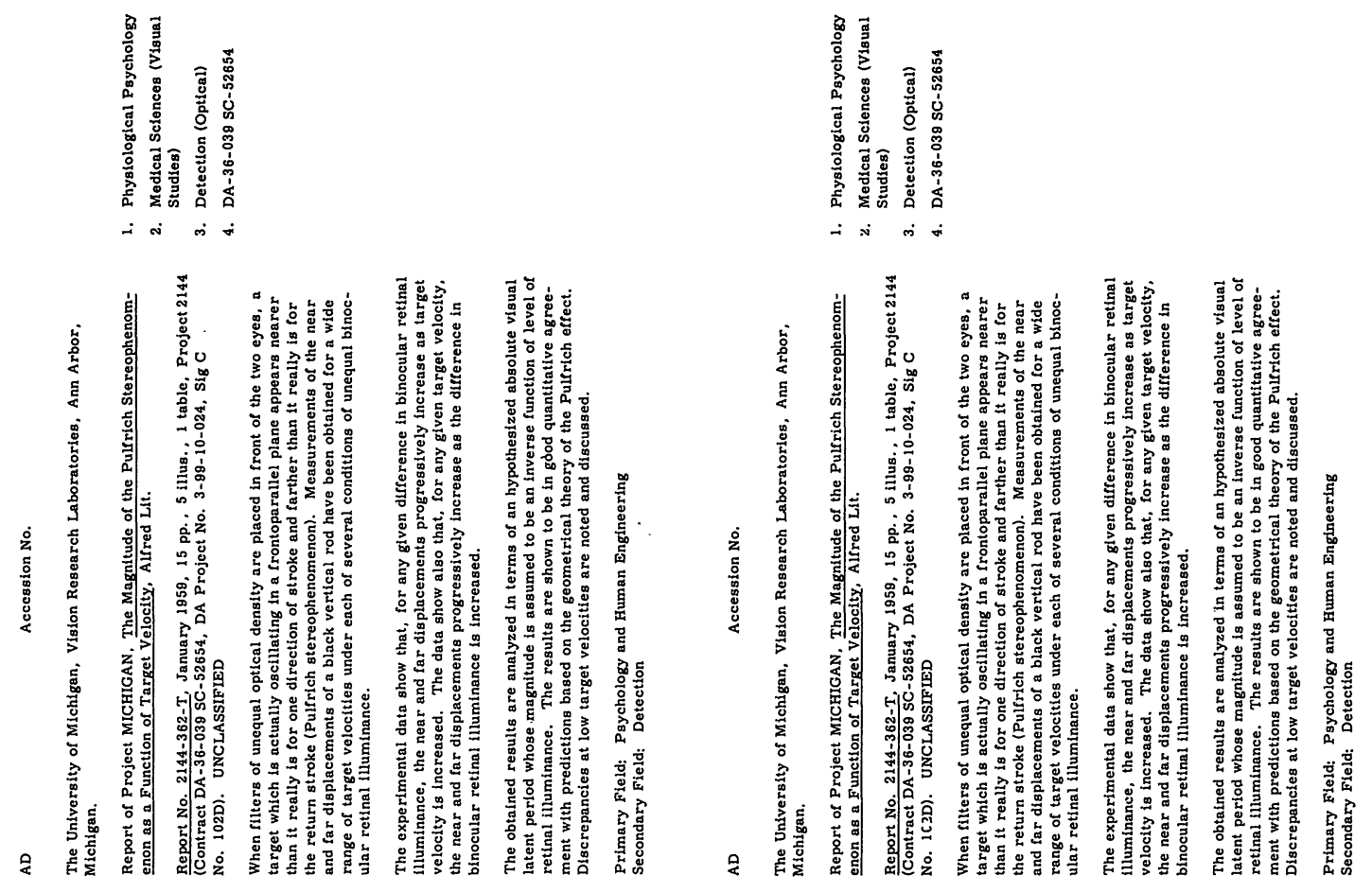

IIII
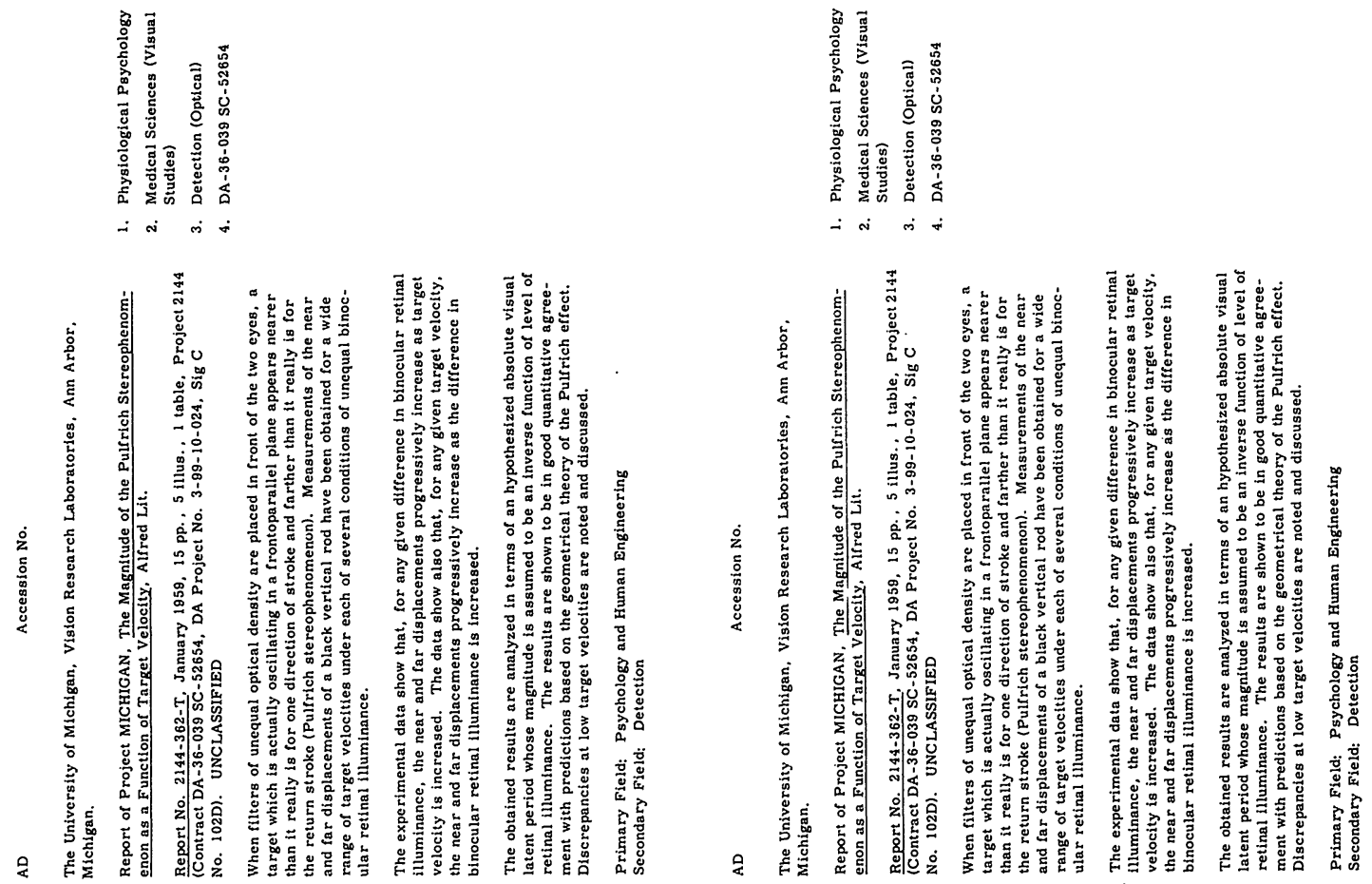
2144-362-T

Report of Project MICHIGAN

\section{THE MAGNITUDE OF THE PULFRICH STEREOPHENOMENON AS A FUNCTION OF TARGET VELOCITY}

Alfred Lit

Vision Research Laboratories

The University of Michigan

January 1959

The University of Michigan

WILLOW RUN LABORATORIES

Ann Arbor, Michigan 
Project MICHIGAN is carried on for the U. S. Army Signal Corps under Department of the Army Prime Contract Number DA-36-039 SC-52654, administered through The University of Michigan Research Institute. 


\begin{abstract}
When filters of unequal optical density are placed in front of the two eyes, a target which is actually oscillating in a frontoparallel plane appears nearer than it really is for one direction of stroke and farther than it really is for the return stroke (Pulfrich stereophenomenon). Measurements of the near and far displacements of a black vertical rod have been obtained for a wide range of target velocities under each of several conditions of unequal binocular retinal illuminance.

The experimental data show that, for any given difference in binocular retinal illuminance, the near and far displacements progressively increase as target velocity is increased. The data show also that, for any given target velocity, the near and far displacements progressively increase as the difference in binocular retinal illuminance is increased.

The obtained results are analyzed in terms of an hypothesized absolute visual latent period whose magnitude is assumed to be an inverse function of level of retinal illuminance. The results are shown to be in good quantitative agreement with predictions based on the geometrical theory of the Pulfrich effect. Discrepancies at low target velocities are noted and discussed.
\end{abstract}





\section{PREFACE}

Project MICHIGAN is a research and development project in the field of combat surveillance which has been carried on by the Willow Run Laboratories of The University of Michigan since 1953 under an Army contract supervised by the Signal Corps. The project is engaged in research and development in various fields of science and engineering to improve combat surveillance methods and equipment to meet the long-range operational requirements of the Army in the field.

Major emphasis is placed on research and development in the areas of optics, vision, infrared, acoustics, seismics, radiometry, radar, and in the fields of datalink, data-processing, data-display, and control and guidance systems for aerial platforms.

In addition, the project develops new combat surveillance concepts and it evaluates them and existing systems through simulation and analysis.

The work reported herein was conducted for Project MICHIGAN by the Vision Research Laboratories of The University of Michigan. 
Progress and results in all reports are continually reassessed by Project MICHIGAN. Comments and suggestions from readers are invited.

DISTRIBUTION OF REPORTS

Distribution control of Project MICHIGAN Reports has been delegated by the U. S. Army Signal Corps to:

Commanding Officer

U. S. Army Liaison Group Project MICHIGAN

Willow Run Laboratories

Ypsilanti, Michigan

It is requested that information or inquiry concerning distribution of reports be addressed accordingly. 


\section{TABLE OF CONTENTS}

\begin{tabular}{llr} 
Section & \multicolumn{1}{c}{ Title } & Page \\
& Abstract & iii \\
& Preface & $\mathrm{v}$ \\
& List of Figures and Tables & ix \\
1 & Introduction and Summary & 1 \\
2 & Background of the Problem & 2 \\
3 & Apparatus and Procedures & 4 \\
4 & Results & 6 \\
5 & Discussion & 8 \\
& References & 11 \\
& Distribution List & 13
\end{tabular}





\section{LIST OF FIGURES AND TABLES}

\begin{tabular}{lrr} 
Figure & \multicolumn{1}{c}{ Title } & Page \\
1 & Geometrical Relationships & 3 \\
2 & $\begin{array}{l}\text { Schematic Representation of the Apparatus } \\
\text { and Observer's View of Stimulus Targets }\end{array}$ & 5 \\
3 & Latency Differences for Target Velocities & 7 \\
4 & Average Latency Differences for Target Velocities & 8 \\
5 & The Hypothesized Absolute Visual Latent Period & 9 \\
& (t) as a Function of Retinal Illuminance (Log E) & \\
Table & Title & Page \\
I & Depth-Displacement Data & 7
\end{tabular}





\section{INTRODUCTION AND SUMMARY}

The present study was designed to yield basic sensory data and to provide appropriate visual theory on an important but relatively neglected aspect of battle area surveillance, that is, on the binocular spatial localization of moving stimulus targets. Of particular interest in the present study is the investigation of a localization error that arises when a transversely moving target is binocularly observed under conditions of unequal binocular retinal illuminance (Pulfrich stereoeffect). Application of the experimental results and their accompanying explanatory theory to problems of the military surveillance task should lead to improved design and more effective operation of binocular optical aids that are utilized for spatial localization of moving battlefield targets.

A target which is oscillating in a frontal plane will appear to rotate out of its plane of oscillation when binocularly viewed with a filter placed in front of one of the eyes. The oscillating target appears nearer than it really is for one direction of stroke and farther than it really is for the return stroke. The near and far displacements of the oscillating target are accounted for in terms of a difference in the hypothesized visual latent periods of the two eyes that results from the inequality of binocular retinal illuminance produced by the filter. When the near and far displacements $\left(\mathrm{C}_{\mathrm{N}}\right.$ and $\left.\mathrm{C}_{\mathrm{F}}\right)$ in the observer's vertical median plane are determined experimentally, it is possible by geometrical analysis of the theory of the Pulfrich effect to calculate the corresponding near and far latency differences $\left(\Delta t_{N}\right.$ and $\left.\Delta t_{F}\right)$.

The purpose of the present experiment is to obtain systematic data on the effects of target velocity on $\mathrm{C}_{\mathrm{N}}$ and $\mathrm{C}_{\mathrm{F}}$. The apparatus used provides an oscillating target in the upper visual field that is free to execute constant linear motion of varying magnitudes in a frontal plane located $100 \mathrm{~cm}$ from the observer's eyes. A binocular fixation target in the lower visual field is used by the observer to localize the oscillating target at its apparent near and far positions for each of 11 target velocities and under each of four conditions of unequal binocular retinal illuminance, $\log \left(\mathrm{E}_{\mathrm{R}} / \mathrm{E}_{\mathrm{L}}\right)$. The range of linear velocities used is from $2.59 \mathrm{~cm} / \mathrm{sec}$ to $68.17 \mathrm{~cm} / \mathrm{sec}$ ( $1.49 \mathrm{deg} / \mathrm{sec}$ to $39.05 \mathrm{deg} / \mathrm{sec}$ as measured at the observer's eyes). The four values of $\log \left(\mathrm{E}_{\mathrm{R}} / \mathrm{E}_{\mathrm{L}}\right)$ used are $0.12,0.58,1.07$, and 1.58, where the illuminance of the left eye, $\log _{\mathrm{L}}$, is kept constant at 2.06 log trolands.

Data obtained from two practiced observers are presented. The average values of the near and far latency differences are plotted as a function of target velocity for each of the four conditions of unequal binocular retinal illuminance. The curve for $\log \left(E_{R} / E_{L}\right)=0.12$ shows that, in accordance with predictions based on the geometrical theory of the Pulfrich effect, the computed average latency difference remains essentially constant as target velocity is progressively increased; a slight upturn in this curve is noted, however, at the lowest target velocity. A greater departure from geometrical theory occurs for the remaining curves; the upturn of these curves above their respective constant levels becomes more marked and occurs at progressively higher values of target velocity as the magnitude of the inequality of binocular retinal illuminance is increased.

The computed latency differences, obtained for any given target velocity, progressively increase as the difference in binocular retinal illuminance is increased. This finding is shown to be entirely consistent with the assumption that the magnitude of the hypothesized absolute visual latent period is an inverse function of the level of retinal illuminance. 


\section{BACKGROUND OF THE PROBLEM}

The present experiment deals with a stereoscopic effect that arises whenever a transversely moving object is viewed under conditions of unequal binocular retinal illuminance. The depth effect was first described and analyzed by Pulfrich (Ref. 1) in 1922, and now bears his name. The stereophenomenon can be simply demonstrated by means of a pendulum-bob that is made to oscillate in a frontoparallel plane and on a level with the observer's eyes. A small target for binocular fixation is positioned in his vertical median plane, directly below the oscillating bob and midway between the end-points of its swing. If a neutral or colored filter is placed in front of one of the eyes while the pendulum-bob is in motion, the bob will appear to rotate out of its plane of oscillation in a horizontal elliptical path that locates the bob nearer than it really is for one direction of stroke, and farther than it really is for the return stroke. The oscillating bob appears to rotate in a clockwise direction (as viewed from above) when the filter is placed before the left eye, and counterclockwise when the filter is placed before the right eye. The stereoeffect becomes noticeable at some threshold difference in binocular retinal illuminance and progressively increases in magnitude as the difference in binocular retinal illuminance is increased.

The explanation of the stereophenomenon given by Pulfrich (Ref. 1) is based on a suggestion by Fertsch that increasing differences in binocular retinal illuminance produce increasing differences in the hypothesized visual latent periods of the two eyes. For either eye, the magnitude of the visual latent period (that is, the magnitude of the hypothesized time delay between the onset of stimulation of any given retinal point in the eye and the arousal of the visual effect that signals the position of the stimulus target in space) is assumed to be a reciprocal function of the prevailing level of retinal illuminance. Hence, for any specified position of the moving target in the frontoparallel plane, the delay in the signal from the given stimulated retinal point in the covered eye will be slightly greater than the signal delay from the simultaneously stimulated corresponding retinal point in the uncovered eye. It must be further assumed that the binocular spatial localization of the moving target, at any given moment, is determined by the given pair of retinal points in the two eyes that yields simulta- neously aroused binocular signals. Accordingly, to yield simultaneously aroused binocular signals from corresponding retinal points, the onset of stimulation for the eye that is covered by the filter must occur when the moving target is at a position farther behind in its path than the position at which the onset of stimulation occurs for the uncovered eye. Thus, simultaneously aroused binocular signals for the transversely moving target are provided by successive pairs of noncorresponding retinal points in the two eyes, and the magnitude of the stereoscopic effect theoretically depends on the amount of the retinal disparity produced as a consequence of the difference in the visual latent periods of the two eyes.

An understanding of the geometric relations involved in the stereophenomenon may be obtained with the aid of Figure 1. The geometric analysis considers the case of a target that is oscillating in a frontoparallel plane with constant linear velocity, $\underline{V}$. The oscillating target is placed at eye level in a frontal plane located at a distance $d$ from the midpoint of the line $\mathrm{Z}_{\mathrm{L}} \mathrm{Z}_{\mathrm{R}}$ which joins the centers of rotation of the two eyes. The linear path of the target in its plane of oscillation is denoted by $\mathrm{W}_{1} \mathrm{~W}_{2}$. As indicated, the filter is placed in front of the left eye.

Figure 1 is meant to represent the stereoscopic space-image in the horizontal plane of fixation for the case in which the oscillating target, $\mathrm{P}_{\mathrm{LR}}$, is moving from left to right, and for the case in which the oscillating target, now designated by $\mathrm{P}_{\mathrm{RL}}$, is moving from right to left. The points $\mathrm{P}_{\mathrm{N}}$ and $\mathrm{P}_{F}^{\prime}$ represent the respective near and far positions at which the oscillating target is supposedly localized by the observer by use of a binocular fixation target movable in the vertical median plane. The distance $O P^{\prime}{ }_{N}$ designates the magnitude of the near displacement, $\mathrm{C}_{\mathrm{N}}$. The distance $\mathrm{OP}_{\mathrm{F}}^{\prime}$ designates the magnitude of the far displacement, $\mathrm{C}_{\mathrm{F}}$.

In accordance with the laws of binocular space discrimination, lines of sight from each eye are drawn through the two respective points of target 
localization, $\mathrm{P}_{\mathrm{N}}^{\prime}$ and $\mathrm{P}_{\mathrm{F}}^{\prime}$. The two points of target localization are assumed to have relative positions of depth in the median plane such that the lines of sight drawn through point $\mathrm{P}^{\prime}{ }_{\mathrm{N}}$ and the lines of sight drawn through point $\mathrm{P}_{\mathrm{F}}^{\prime}$ intersect the line $\mathrm{W}_{1} \mathrm{~W}_{2}$ at the same two points, $\underline{A}$ and $\underline{B}$. The intersection points $\underline{A}$ and $\underline{B}$ theoretically mark the respective positions in the path of the oscillating target at which onset of stimulation occurred in each of the two eyes. Thus, when the target is moving from left to right and appears to be located at the far position, $\mathrm{P}^{\prime} \mathrm{F}^{\prime}$, the onset of stimulation for the right eye occurred when the target (now at $\mathrm{P}_{\mathrm{LR}}$ ) was located at point $\underline{B}$, and the onset of stimulation for the left eye covered by the filter occurred when the target was located at point $\mathrm{A}$, a bit farther behind in its path. The time taken for the target to move from $\underline{B}$ to $P_{L R}$ represents the magnitude of the visual latent period of the right eye, and the time taken for the target to move from $\mathrm{A}$ to $\mathrm{P}_{\mathrm{LR}}$

represents the slightly larger magnitude of the visual latent period of the left eye. Consequently, the time taken for the target to move from $\underline{A}$ to $\underline{B}$ represents the difference, $\Delta \mathrm{t}_{\mathrm{F}}$, in the visual latent periods of the two eyes, based on the far position of target localization, $\mathrm{P}_{\mathrm{F}}^{\prime}$. Since the velocity of the oscillating target is identical for either direction of movement, it follows by the same reasoning that when the target is moving from right to left and appears to be located at the near position, $\mathrm{P}^{\prime} \mathrm{N}^{\prime}$, the onset of stimulation for the right eye occurred when the target (now at $\mathrm{P}_{\mathrm{RL}}$ ) was located at point $\underline{A}$, and the onset of stimulation for the left eye covered by the filter occurred when the target was located at point $B$, a bit further behind in its path. In this case, the time taken for the target to move from $B$ to $A$ represents the difference, $\Delta t_{N}$, in the visual latent periods of the two eyes, based on the near position of target localization, $\mathrm{P}^{\prime} \mathrm{N}$. It should be noted that the latency differences based on the near and the far positions of target localization are theoretically equal in magnitude, that is, $\Delta \mathrm{t}_{\mathrm{N}}=\Delta \mathrm{t}_{\mathrm{F}}$.

If, for any given difference in binocular retinal illuminance, the magnitude of the near and far dis- placements, $\mathrm{C}_{\mathrm{N}}$ and $\mathrm{C}_{\mathrm{F}}$, are experimentally determined, it is possible to calculate the magnitude of the corresponding near and far latency differences, $\Delta t_{N}$ and $\Delta t_{F}$, if the linear velocity, $\underline{V}$, of the oscillating target is known.

It can be readily seen from similar triangles in Figure 1 that for target localizations at $\mathrm{P}_{\mathrm{N}}^{\prime}$ and $\mathrm{P}^{\prime} \mathrm{F}^{\prime}$ respectively,

$$
\underline{\mathrm{X}}=\underline{\mathrm{b}} \underline{\mathrm{C}}_{\mathrm{N}} /\left(\underline{\mathrm{d}-\mathrm{C}_{\mathrm{N}}}\right) \text { and } \underline{\mathrm{X}}=\underline{\mathrm{b}} \underline{\mathrm{C}}_{\mathrm{F}} /\left(\underline{\mathrm{d}}+\underline{\mathrm{C}}_{\mathrm{F}}\right)
$$

where $\underline{X}=1 / 2$ the distance from $\underline{A}$ to $\underline{B}$ and $\underline{b}=1 / 2$ the distance between the centers of rotation of the two eyes. The distance of the plane of oscillation, d, and the near and far displacements, $\mathrm{C}_{\mathrm{N}}$ and $\mathrm{C}_{\mathrm{F}}$, have been previously defined.

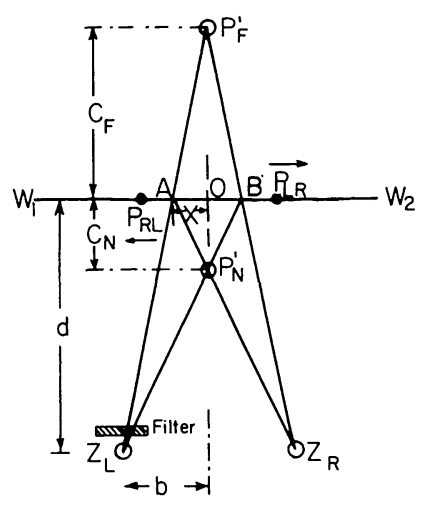

FIG. 1 GEOMETRICAL RELATIONSHIPS Geometrical representation of the Pulfrich stereophenomenon indicating the stereoscopic space-image in the horizontal plane of fixation.

For an oscillating target moving with constant linear velocity, $\underline{V}$, the time taken for the target to pass through the distance $\underline{X}$ is given by the formula,

$$
t=\frac{\underline{X}}{\underline{V}} \text {. }
$$

The time taken for the target to move from $\mathrm{A}$ to $B$ (or $B$ to $A$ ) represents the latency differencé, $\Delta t$, between the two eyes. Since $\underline{\Delta t}=\underline{2 t}$, we obtain from Equation 2,

$$
\Delta t=\frac{2 X}{\underline{V}} .
$$


Substituting for $X$ the respective expressions given in Equation 1, we finally obtain the following relationship between the experimentally determined near and far displacements $\left(\mathrm{C}_{\mathrm{N}}\right.$ and $\left.\mathrm{C}_{\mathrm{F}}\right)$ and the corresponding computed near and far latency differences $\left(\Delta t_{N}\right.$ and $\left.\Delta t_{F}\right)$ :

$$
\Delta \mathrm{t}_{\mathrm{N}}=\frac{2 \underline{\mathrm{b}}}{\underline{\mathrm{v}}} \cdot \frac{\mathrm{C}_{\mathrm{N}}}{\underline{\underline{\mathrm{d}}-\mathrm{C}_{N}}}
$$

and

$$
\Delta t_{F}=\frac{2 \underline{b}}{\underline{v}} \cdot \frac{C_{F}}{\underline{d}+C_{F}} .
$$

It should be noted from purely geometric considerations that, for any constant difference in binocular retinal illuminance, the magnitude of the stereoscopic effect as measured by $\mathrm{C}_{\mathrm{N}}$ and $\mathrm{C}_{\mathrm{F}}$ should progressively increase as the linear velocity of the oscillating target is increased, but the corresponding calculated values of $\Delta t_{N}$ and $\Delta t_{F}$ should remain constant for all target velocities used.
The present experiment is a continuation of a research program (Ref. 2, 3) designed to obtain systematic data on some of the important stimulus variables that influence the magnitude of the Pulfrich effect. The aim of the research program is to provide appropriate data that ultimately can be directly related to theories and data concerned with several basic visual functions: (a) binocular space discrimination; (b) the relationship between the magnitude of the monocular visual latent period and level of retinal illuminance; (c) intensity discrimination; (d) retinal interaction; and (e) color vision. In the present experiment, the effect of target velocity is systematically studied. This is an important variable whose effect on the magnitude of the stereoeffect (that is, on $\mathrm{C}_{\mathrm{N}}$ and $\mathrm{C}_{\mathrm{F}}$ ) can be predicted on the basis of the geometric theory of the Pulfrich effect. The present experiment thus provides a direct test of the adequacy of the proposed theory. It will also provide data that can be related to classical theory of binocular space discrimination and to theories concerned with retinal interaction effects of moving targets.

\section{APPARATUS AND PROCEDURES}

A schematic representation of the apparatus ${ }^{*}$ is presented in Figure 2A. A detailed description is available in a previous report (Ref. 3). The apparatus consists of three major components: (a) the oscillating target, (b) the fixation target, and (c) the lighting and screening units.

The observer is seated in a dark room (D) and binocularly observes the fixation target ( $\underline{\mathrm{FT}})$ and the oscillating target (OT) through a pair of circular artificial pupils (E) that are $2.5 \mathrm{~mm}$ in diameter and adjustable for interpupillary separation. The artificial pupils are attached to eye-tubes which are mounted on the inner wall of the dark room. In front of each eye-tube, a filter box $(F)$ is mounted on the outer wall so that the experimenter can control the retinal illuminance of each eye by combinations of neutral density filters. The observer's

\footnotetext{
* The apparatus was originally constructed at Pupin Laboratories, Columbia University, partially through funds from a research grant-in-aid generously provided by the American Academy of Optometry.
}

head is kept immobilized by means of chin and forehead rests.

The oscillating target ( $\underline{\mathrm{OT}}$ ) is a blackened steel $\operatorname{rod} 1 / 8$ inch in diameter. It is vertically suspended downward to eye level from a Jacobs chuck in which it is retained. The chuck is centrally mounted on the undersurface of a supporting carriage which rides on horizontal tracks (T) located in a frontal plane at a distance of $100 \mathrm{~cm}$ from the observer's eyes. The carriage receives its movement from a horizontally oscillating drive-rod $(\underline{R})$ which is pivoted at position $\mathrm{O}$, a point located in the observer's median plane directly above the midpoint of the line joining the two eyes. Power for the drive-rod is provided by a cam-regulated mechanism (C) which converts constant angular velocity into reciprocating linear velocity, with the central 90 percent of stroke at constant speed. The power to the drive-rod is applied at a vertical pivot point (P) permanently mounted on the driverod. The electrically driven gear train (M) shown in Figure 2A was replaced by a Zero-Max (Revco, Inc., Model 143) variable speed transmission 
device to allow adjustments of the linear velocity of the oscillating target over a wide range of values. Calibration of the transmission device was achieved by measuring the time required for the supporting carriage of the oscillating target to move through a fixed distance of $10 \mathrm{~cm}$ in the central region of the elevated tracks (T) on which it rides. The time measurements were performed with an Electronic Precision Chronoscope (Wichita Apparatus Supply, Inc., Model 251). Thus, the linear velocity of the oscillating target is specified for all positions of the lever arm of the speed control link.

The fixation target (FT) is a blackened steel $\operatorname{rod} 1 / 8$ inch in diameter. It is held vertically upright to eye level in a Jacobs chuck that is mounted on the upper surface of a supporting carriage located below eye level. The comparison rod and its supporting carriage are movable along a horizontal metal track (J) located in the observer's vertical median plane. By means of a pulleywheel (W) located in the dark room, the observer can adjust the position of the fixation target in a direction either towards or away from his eyes. The distance of the fixation target from the observer's eyes, as measured along the metal track, can be read by the experimenter from a scale calibrated in millimeters. The use of a vernier index permits the experimenter to estimate the distance of the fixation target to within $0.01 \mathrm{~cm}$. The height of the upper end of the fixation target is set on a level with the observer's eyes. Thus, when the oscillating target is at a position directly above the fixation target, the targets appear contiguous in the observer's vertical median plane. At this distance $(100 \mathrm{~cm})$ from the observer's eyes, the diameter of each rod subtends a visual angle of 10. 9 minutes of arc.

Uniform background illumination is provided by ten 150-watt frosted lamps that are appropriately mounted in an asbestos-lined, galvanized iron lightbox (L). The light-box is located in a frontal plane $250 \mathrm{~cm}$ from the observer's eyes. Lamp voltage is maintained constant (to within \pm 1.0 percent) at 124 volts a-c by means of an automatic constantvoltage output regulator. The illuminated surface is a white-matte screen that is attached to the inner rear wall of the light-box. The surface has a luminance of 854 foot-lamberts as measured with a Macbeth illuminometer. The color temperature at the given voltage is $2735^{\circ} \mathrm{K}$. With the $2.5 \mathrm{~mm}$ artificial pupil in use, the retinal illuminance without filters is 14359 trolands or 4.16 log trolands.

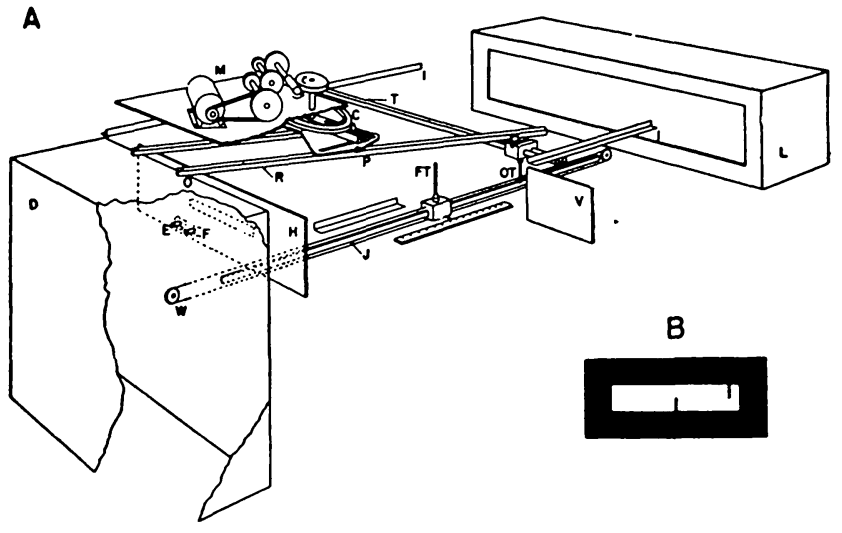

FIG. 2 SCHEMATIC REPRESENTATION OF THE APPARATUS AND OBSERVER'S VIEW OF STIMULUS TARGETS A. The observer is seated in a dark room (D) and binocularly observes the fixation target (FT) located in the lower visual field and the oscillating target (OT) located in the upper visual field through a pair of artificial pupils (E). Movement of the oscillating target in a frontoparallel plane $100 \mathrm{~cm}$ from the observer's eyes can be varied over a wide range of constant linear velocities. The fixation target in the observer's vertical median plane can be moved either toward or away from his eyes by means of a pulley-wheel $(\underline{W})$ located in the dark room. Background illumination is provided by a light-box ( $\underline{L})$. The retinal illuminance of each eye is controlled by neutral density filters placed in the pair of filter boxes (F). Horizontal ( $\underline{\mathrm{H}})$ and vertical (V) screens provide a constant rectangular field of view.

B. The upper rod is the oscilating target; the lower rod is the fixation target. [From Lit and Hyman (Ref. 3)]

The field of view in the vertical direction is kept constant at $4.2^{\circ}$ by a horizontal slit $(26 \mathrm{~cm} \times 1.5 \mathrm{~cm})$ cut at eye level in a black vertical screen $(\underline{H})$ located $21 \mathrm{~cm}$ in front of the observer. The field of view in the horizontal direction is kept constant at $21.6^{\circ}$ by means of a pair of vertical screens (V) [only one screen is shown in Fig. 2A] adjusted symmetrically in the plane of the oscillating target, $0.5^{\circ}$ beyond the end-points of its reciprocating stroke. The view of the targets as seen by the observer is shown in Figure 2B.

Two trained graduate students who were emmetropic served as paid observers. The monocuiar visual acuity of each observer was better than $20 / 20$, and the ductions of each were normal at both distance and near. At a fixation distance of $100 \mathrm{~cm}$, the interpupillary separation for observer F.C. was $6.20 \mathrm{~cm}$ and that for observer M. M. was $6.70 \mathrm{~cm}$. At this fixation distance, the phoria for observer F.C. was $3^{\Delta}$ exophoria and that for observer M.M. was $1^{\Delta}$ esophoria. 
Daily practice sessions were held for a period of about a month during which the observers were trained in the procedure of localizing the apparent near and far positions of the oscillating target at various target velocities and under different amounts of unequal binocular retinal illuminances, Log $\left(E_{R} / E_{L}\right)$. In performing his settings, the observer continuously fixates the upper end of the movable fixation rod and adjusts this rod in the vertical median plane until it appears to lie directly below the near and far paths of the oscillating target. The apparent near and far positions of the oscillating target are each localized first when the fixation rcil is moved away, and again when it is moved toward the observer. In this way, multiple pairs of determinations of $\mathrm{C}_{\mathrm{N}}$ and $\mathrm{C}_{\mathrm{F}}$ can be obtained under any given set of viewing conditions. With filters of equal optical density in front of the eyes, only a single path of the oscillating target was reported, that is, no Pulfrich effect was elicited at any given velocity under conditions of equal binocular retinal illuminance.

Settings for the apparent near and far positions of the oscillating target were obtained from both observers at each of 11 target velocities, V: 2.59, $5.90,8.16,10.28,13.76,19.96,26.86,35.56$,
$45.01,55.53$, and $68.17 \mathrm{~cm} / \mathrm{sec}$. For target movement in a frontoparallel plane located $100 \mathrm{~cm}$ from the observer's eyes, these values of linear velocity correspond to the following angular velocities: 1.49 , $3.38,4.68,5.89,7.88,11.44,15.39,20.37,25.78$, 31.81 , and $39.05 \mathrm{deg} / \mathrm{sec}$. In a given experimental session only one target velocity was used and five pairs of settings ( 10 readings each for $\mathrm{C}_{\mathrm{N}}$ and $\mathrm{C}_{\mathrm{F}}$ ) were obtained from each observer for each of four conditions of increasing inequality of binocular retinal illuminance, $\log \left(\mathrm{E}_{\mathrm{R}} / \mathrm{E}_{\mathrm{L}}\right)$. The retinal illuminance of the left eye ( $\left.\log \mathrm{E}_{\mathrm{L}}\right)$ was held constant at $2.06 \log$ trolands by use of a neutral filter of optical density 2.10. The retinal illuminance of the right eye ( $\log \mathrm{E}_{R}$ ) was successively increased by use of neutral filters of optical densities $1.98,1.52,1.03$, and 0.52. Thus, the four values of $\log \left(\mathrm{E}_{\mathrm{R}} / \mathrm{E}_{\mathrm{L}}\right)$ used at each of the 11 target velocities were: 0.12 , $0.58,1.07$, and 1.58. A total of 22 experimental sessions was held for each observer. A counterbalanced order was introduced for target velocity. That is, for the first 11 sessions, the target velocity was presented in order of increasing magnitude, and for the second 11 sessions, the target velocity was presented in decreasing order.

\section{RESULTS}

The results for both observers are presented in Table I. Each entry of $\mathrm{C}_{\mathrm{N}}$ and $\mathrm{C}_{\mathrm{F}}$ represents the mean value (in centimeters) of two sets of 10 readings obtained at each target velocity under each of the four specified conditions of unequal binocular retinal illuminance.

Inspection of Table I reveals that, for any given value of $\log \left(E_{R} / E_{L}\right), C_{N}$ anc $C_{F}$ progressively increase as target velocity is increased. $\mathrm{C}_{\mathrm{N}}$ and $\mathrm{C}_{\mathrm{F}}$ also progressively increase as $\log \left(\mathrm{E}_{\mathrm{R}} / \mathrm{E}_{\mathrm{L}}\right)$ is increased at any given target velocity. A characteristic individual difference in performance should be noted: for observer F.C., the values of $\mathrm{C}_{\mathrm{N}}$ are consistently larger than the corresponding values of $\mathrm{C}_{\mathrm{F}}$; for observer M.M., contrariwise, the values of $\mathrm{C}_{\mathrm{N}}$ are consistently smaller than the corresponding values of $\mathrm{C}_{F^{\circ}}$

To facilitate analysis of these data in terms of the geometric theory of the Pulfrich effect, the corresponding latency differences, $\Delta t_{N}$ and $\Delta t_{F}$, have been computed from Equation 4 for each set of values of $\mathrm{C}_{\mathrm{N}}$ and $\mathrm{C}_{\mathrm{F}}$ given in Table $\mathrm{I}$. The results of the computation are shown graphically in Figure 3 where $\Delta t_{N}$ and $\Delta t_{F}$ (in milliseconds) are plotted for each observer as a function of target velocity (in $\mathrm{deg} / \mathrm{sec})$ with $\log \left(\mathrm{E}_{\mathrm{R}} / \mathrm{E}_{\mathrm{L}}\right)$ serving as parameter. A similar plot of the averages of the near and far latency differences, $\overline{\Delta t}$, for the combined data of both observers is shown in Figure 4. 
TABLE I

DEPTH-DISPLACEMENT DATA Depth displacements obtained at each of 11 target velocities under four conditions of unequal binocular retinal illuminance, $\log \left(E_{R} / E_{L}\right)$. The retinal illuminance of the left eye, $\log E_{L}$, was kept constant at $2.06 \log$ trolands. $\frac{C_{N}}{C_{N}} C_{F}$ refer, respectively, to the near and far displacements of a target oscillating in a frontoparallel plane located $100 \mathrm{~cm}$ from the observer's eyes. Each entry for the two observers (F.C. and M.M.) is based on the mean of 20 settings. The thickness of the stimulus target used was $0.125 \mathrm{inch}$.

\begin{tabular}{|c|c|c|c|c|c|c|c|c|c|c|c|c|c|c|c|c|}
\hline $\begin{array}{l}\text { Target } \\
\text { Velocity } \\
(\mathrm{cm} / \mathrm{sec})\end{array}$ & $\begin{array}{l}\text { Lo } \\
\frac{\mathrm{C}_{\mathrm{N}}}{(\mathrm{cm})}\end{array}$ & \multicolumn{2}{|c|}{$\begin{array}{l}\log \left(E_{R} / E_{L}\right)=0.12 \\
\underline{\text { F.C. }}\end{array}$} & $\begin{array}{l}12 \\
\frac{{ }_{\mathrm{F}}}{(\mathrm{cm})}\end{array}$ & \multicolumn{4}{|c|}{$\begin{array}{l}\log \left(E_{R} / E_{L}\right)=0.58 \\
\text { F.C. }\end{array}$} & \multicolumn{4}{|c|}{$\begin{array}{l}\log \left(E_{R} / E_{L}\right)=1.07 \\
\text { F.C. }\end{array}$} & $\begin{array}{l}\text { Lo } \\
\frac{\mathrm{C}_{\mathrm{N}}}{(\mathrm{cm})}\end{array}$ & \multicolumn{3}{|c|}{$\begin{array}{l}\log \left(E_{R} / E_{L}\right)=1.58 \\
\underline{\text { F.C. }} .\end{array}$} \\
\hline 2.59 & .13 & 0.20 & 0.33 & 0.39 & 0.48 & 0.46 & 0.63 & 0.59 & 0.74 & 0.75 & 0.85 & 0.82 & 0.95 & 0.98 & 1.07 & 1.03 \\
\hline 5.90 & 0.27 & 0.19 & 0.44 & 0.42 & 0.80 & 0.70 & 0.85 & 0.94 & 1.28 & 1.16 & 1.37 & 1.35 & 1.63 & 1.48 & 1.93 & 1.93 \\
\hline 8.16 & 0.41 & 0.27 & 0.35 & 0.62 & 1.12 & 0.97 & 1.09 & 1.22 & 1.55 & 1.48 & 1.67 & 1.63 & 1.99 & 1.90 & 2.17 & 2.27 \\
\hline 96 & 1.31 & 0.19 & 0.61 & 1.29 & 2.69 & 1.61 & 2.15 & 2.64 & 3.52 & 2.73 & 3.30 & 3.76 & 4.12 & 3.45 & 3.74 & 4.99 \\
\hline 26.86 & 2.01 & 0.82 & 0.72 & 1.67 & 3.54 & 2.23 & 2.67 & 3.60 & 4.64 & 3.24 & 3.74 & 5.18 & 5.98 & 4.54 & 4.80 & 6.38 \\
\hline 35.56 & 2.58 & 0.57 & 0.87 & 2.23 & 4.77 & 2.21 & 2.42 & 4.21 & 6.07 & 3.49 & 4.52 & 6.74 & 7.41 & 5.27 & 5.77 & 8.88 \\
\hline 45.01 & 3.15 & 0.58 & 0.97 & 2.01 & 5.45 & 2.50 & 3.43 & 4.64 & 7.32 & 4.33 & 5.37 & 7.85 & 9.08 & 6.35 & 6.82 & 9.48 \\
\hline 55.53 & 3.72 & 0.05 & 0.77 & 2.79 & 6.62 & 2.13 & 4.41 & 6.63 & 8.93 & 3.73 & 6.88 & 9.45 & 10.70 & 6.21 & 8.42 & 12.33 \\
\hline 68.17 & 4.22 & 0.02 & 0.60 & 5.70 & 7.50 & 1.45 & 4.46 & 9.89 & 10.66 & 3.46 & 7.64 & 13.30 & 12.57 & 5.95 & 9.40 & 15.74 \\
\hline
\end{tabular}
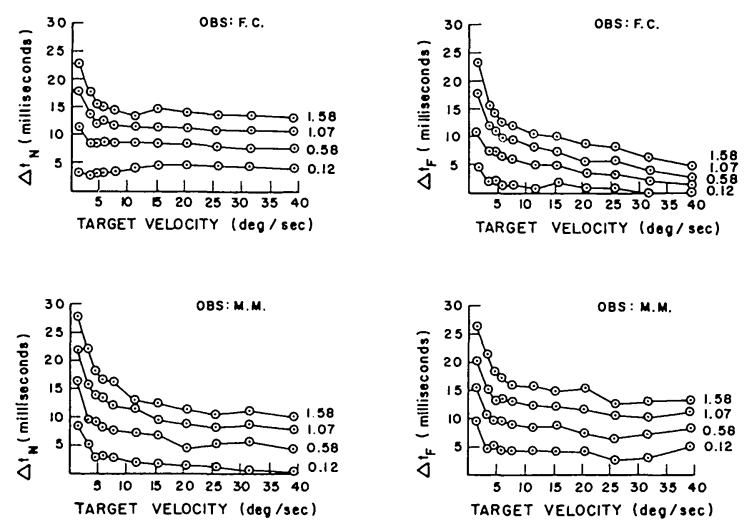

FIG. 3 LATENCY DIFFERENCES FOR TARGET VELOCITIES Latency differences as a function of target velocity for four conditions of unequal binocular retinal illuminance. The latency differences $\left(\Delta t_{N}\right.$ and $\left.\Delta_{F}\right)$ were computed from Equation 4 for the corresponding near and far displacements $\left(C_{N}\right.$ and $\left.C_{F}\right)$ given in Table $I$. The number accompanying $\frac{\mathrm{N}}{\text { each }} \frac{\mathrm{F}}{\mathrm{f}}$ curve reprents the prevailing magnitude of $\mathrm{Log}$ $\left(E_{R} / E_{L}\right)$, where the retinal illuminance of the left eye, Log $\mathrm{E}_{\mathrm{L}}$, is kept constant at $2.06 \mathrm{log}$ trolands. Each point is based on the mean of 20 readings.
The curves in Figure 3 and Figure 4 for Log $\left(\mathrm{E}_{\mathrm{R}} / \mathrm{E}_{\mathrm{L}}\right)=0.12$ show that the computed values of $\Delta \mathrm{t}_{\mathrm{N}}, \overline{\Delta t}_{\mathrm{F}}$, and $\overline{\Delta t}$ remain essentially constant as target velocity is progressively increased. A slight upturn occurs, however, at the lowest target velocity for the curves representing this condition of slightly unequal binocular retinal illuminance. For the remaining curves, the upturn above their respective constant levels becomes more marked and occurs at progressively higher values of target velocity as the magnitude of inequality of binocular retinal illuminance is increased; for the curves representing $\log \left(E_{R} / E_{L}\right)=1.58$, the computed latency differences seem to be independent of target velocity for velocities greater than about $20 \mathrm{deg} / \mathrm{sec}$. It is also to be noted from Figure 3 and Figure 4 that, at any given target velocity, the computed latency differences progressively increase in magnitude as $\log \left(E_{R} / E_{L}\right)$ is increased. 


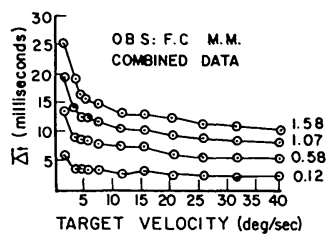

FIG. 4 AVERAGE LATENCY DIFFERENCES FOR TARGET VELOCITIES Average latency differences as a function of target velocity for four conditions of unequal binocular retinal illuminance, $\log \left(\mathrm{E}_{R} / \mathrm{E}_{L}\right)$. The average latency differences, $\Delta t$, were obtained by combining the values of $\Delta t_{N}$ and $\Delta t{ }_{F}$ in Figure 3 for both observers. Thus, each point is based on the mean of 40 readings.
The individual difference previously noted with respect to the relative magnitudes of $\mathrm{C}_{\mathrm{N}}$ and $\mathrm{C}_{\mathrm{F}}$ also prevails with respect to the relative magnitudes of $\Delta t_{N}$ and $\Delta t_{F}$ : for observer F.C., the values of $\Delta t_{N}$ $\overline{\text { are }}$ consistently larger than the corresponding values of $\frac{\Delta t_{F}}{}$; for observer M.M., the values of $\Delta t_{N}$ are consistently smaller than the corresponding values of $\Delta t_{F}$. 5

\section{DISCUSSION}

Of all stimulus factors known to influence the magnitude of the Pulfrich sterophenomenon, target velocity has been the variable most frequently studied by previous investigators. See, for example, experiments by Pulfrich (Ref. 1), Engelking and Poos (Ref. 4), Banister (Ref. 5), Wolfflin (Ref. 6), Arndt (Ref. 7), Holz (Ref. 8), and Liang and Piéron (Ref. 9). Although in most of these experiments displacement settings were obtained for only limited ranges of target velocity or for only a single condition of unequal binocular retinal illuminance, the results invariably showed that the values of $\mathrm{C}_{\mathrm{N}}$ and $\mathrm{C}_{\mathrm{F}}$ were smallest at the lowest target velocity and progressively increased as target velocity was increased. The corresponding absolute magnitudes of the computed latency differences, $\Delta t_{N}$ and $\Delta t_{F}$, reported by these investigators, revealed considerable variability. When a dense blue filter was placed in front of one eye, Arndt (Ref. 7) found a computed latency difference of 1917 milliseconds for a target velocity of $0.04 \mathrm{deg} / \mathrm{sec}$ and a computed latency difference of 110 milliseconds for a target velocity of 6.67 $\mathrm{deg} / \mathrm{sec}$. These data thus show a 17 -fold decrease in latency difference as target velocity undergoes a 170 -fold increase in magnitude. In contrast, the data of Holz (Ref. 8) revealed that, for a given blue filter, a computed latency difference of 97 milliseconds was obtained for a target velocity of $0.65 \mathrm{deg} / \mathrm{sec}$ and a computed latency difference of 16 milliseconds was obtained for a target velocity of $23,23 \mathrm{deg} / \mathrm{sec}$. In this case, latency difference undergoes only about a 6 -fold change. Holz also reported that the computed latency difference showed no further decrease in magnitude (below 16 milliseconds) as target velocity was respectively increased to values of 40.42 and $130.53 \mathrm{deg} / \mathrm{sec}$.
The data of the present experiment (that is, the curves given in Fig. 4) seem to show better agreement with predictions based on the geometrical theory of the Pulfrich effect. For each of the specified differences of binocular retinal illuminance used, the respective magnitude of the computed average latency difference, $\overrightarrow{\Delta t}$, remains essentially constant as target velocity is systematically varied. Discrepancies appear primarily at low target velocities, particularly for the experimental curves representing large values of $\log \left(\mathrm{E}_{\mathrm{R}} / \mathrm{E}_{\mathrm{L}}\right)$. These discrepancies reflect the fact that, as target velocity is progressively decreased, the values of $\mathrm{C}_{\mathrm{N}}$ and $\mathrm{C}_{\mathrm{F}}$ obtained for the given curve become systematically slightly larger than the respective theoretical values required by Equation 4 to yield a given constant $\overline{\Delta t}$ for all target velocities.

A similar discrepancy for low target velocities occurs in the so-called sensation-time (Empfindungszeit) experiments of Frohlich (Ref. 10) in which a vertical slit of light is moved in a frontoparallel plane directly behind a horizontal opening in a screen. To an observer placed directly in front of the screen, the moving target typically does not appear to come into view at the entrance edge of the horizontal cpening but rather at some small lateral distance within the border of the screen aperture. Frohlich attributed this effect to the visual latent period (die Empfindungszeit). He proposed that the magnitude of the sensationtime for any given set of observation conditions could be computed from the time difference between the actual and seen appearance of the moving target, that is, sensation-time $=\underline{d} / \underline{v}$, where $\underline{d}$ is the lateral distance from the entrance edge at which the vertical target first appears to come into view and $\mathrm{v}$ is the linear velocity of the target in its frontoparallel path. 
Experiments on the effects of target velocity [see, for example, Holz (Ref. 8)] yielded sensation-time vs target velocity curves for various target luminances that also characteristically show an upturn at low target velocities (that is, as target velocity is progressively decreased, the respective lateral distances from the entrance edge at which the target is localized by the observer become progressively smaller but at a rate considerably slower than that required to yield a given constant computed sensation-time for all target velocities). Holz (Ref. 8) obtained sensation-time measures under stimulus conditions (that is, for target velocities and luminances) that were identical to those prevailing in his experiment on the Pulfrich effect. His results showed that, for each of the given target velocities, the computed sensation-time for the target having lower luminance minus the computed sensationtime for the target having higher luminance yielded a value that was numerically equal to the respective computed latency difference obtained in his experiment on the Pulfrich effect.

Additional experiments on the effects of target velocity are required to clarify the reasons for the upturns in the latency-difference vs target velocity curves of Figure 4. Of particular interest in this connection would be the results of additional experiments in which the thickness of the oscillating target is systematically varied and in which specified differences of binocular retinal illuminances are produced at many basic levels of illuminance.

The present experiment also provides data on the effects of specified differences in binocular retinal illuminance on the magnitude of the near and far displacements and their corresponding computed latency differences. The data show that, for each of the given target velocities, displacements $\mathrm{C}_{\mathrm{N}}$ and $\mathrm{C}_{\mathrm{F}}$ and their corresponding calculated latency differences, $\Delta t_{N}$ and $\Delta t_{F}$, progressively increase as $\log \left(E_{R} / E_{L}\right)$ is increased. As in the case of similar data obtained is an earlier experiment [Lit, (Ref. 2)], the effects of variations in the magnitude of $\log \left(\mathrm{E}_{R} / \mathrm{E}_{L}\right)$ can be accounted for if the assumption is made that the hypothesized absolute visual latent period, $t$, is an inverse function of retinal illuminance, $\log \underline{E}$. A schematic representation of this relationship is shown in Figure 5. In this figure, $\log \mathrm{E}_{\mathrm{L}}$ represents the constant retinal illuminance of the left eye, and $\mathrm{Log}$ $\mathrm{E}_{\mathrm{R} 1}$, Log $\mathrm{E}_{\mathrm{R} 2}$, and $\log \mathrm{E}_{\mathrm{R} 3}$ represent the increased retinal illuminance successively produced in the right eye. It can be readily seen with the aid of Figure 5 that the difference in absolute latency $(\Delta t)$ theoretically increases as the difference in binocular retinal illuminance $\left[\log \left(\mathrm{E}_{R} / \mathrm{E}_{L}\right)\right]$ is increased. The specific rate of increase theoretically depends, of course, on the initial magnitude selected for the retinal illuminance of the left eye $\left(\log E_{L}^{*}\right)$.

When the data of the present experiment are plotted to show how $\overline{\Delta t}$ varies as a function of $\mathrm{Log}$ $\left(\mathrm{E}_{\mathrm{R}} / \mathrm{E}_{\mathrm{L}}\right)$, with target velocity serving as parameter, the obtained curves (not given here) are in quantitative agreement with predictions based on the analysis of Figure 5. The curves do not, however, overlap nor show the same shape for all target velocities. The curves representing low target velocities (below 10 $\mathrm{deg} / \mathrm{sec}$ ) are considerably displaced progressively upward on the ordinate axis and show a relatively more rapid rise in $\overline{\Delta t}$ as $\log \left(E_{R} / E_{L}\right)$ is increased. These effects, of course, reflect the lack of parallelism exhibited in the curves of Figure 4.

From data obtained in an earlier experiment [Lit (Ref.2)], it is possible to determine an empirical equation which describes the relationship existing between the hypothesized absolute visual latent

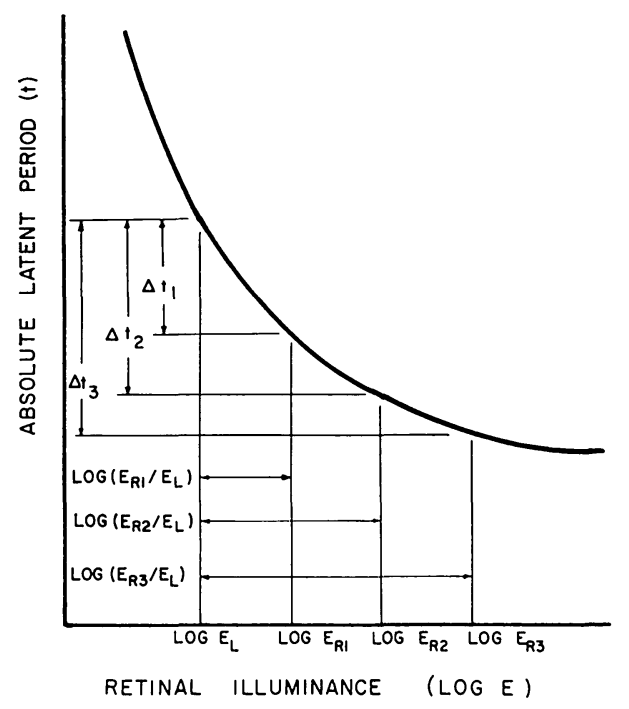

FIG. 5 THE HYPOTHESIZED ABSOLUTE VISUAL LATENT PERIOD (t) AS A FUNCTION OF RETINAL ILLUMINANCE (LOG E) The curve represents an assumed relationship proposed to account for the experimental fact that, for the given constant retinal illuminance of the left eye ( $\left.\log E_{L}\right)$, latency difference $(\Delta t)$ increases progressively as the difference in binocular retinal illuminance $\left[\log \left(\mathrm{E}_{R} / \mathrm{E}_{L}\right)\right]$ is 
period ( $t$ ) and level of retinal illuminance ( Log $E$ ). The necessary computations were deferred pending the outcome of additional experiments concerned with evaluating the effects of systematic variations in distance of observation of the oscillating target, target velocity, and target thickness. It has since been established [Lit and Hyman (Ref. 3)] that latency difference is independent of distance of target oscillation. The present experiment demonstrates that for small differences of binocular retinal illuminance, latency difference is independent of target velocity over a very wide range of velocities. The effects of systematic variations in target thickness will be studied next and the results reported separately.

Finally, mention should be made of the localization error that exists for the moving target when viewed under conditions of equal binocular retinal illuminance. For the observers used in the previous experiments (Ref. 2, 3), the oscillating target appeared to be moving in a frontoparallel plane located nearer than the plane defined by the "true" distance of the oscillating rod. The localization error occurred at all levels of equal retinal illuminance (Ref. 2) and at all distances of observation (Ref. 3). A similar localization error occurred for the observers used in the present experiment. At all target velocities, the oscillating target appeared nearer than the true plane of oscillation for observer F.C. and farther than the true plane of oscillation for observer M.M. It should be pointed out that the magnitude of the localization error for each observer was insufficient to establish equality between the corresponding near and far computed latency-differences. Thus, when the corresponding values of $\mathrm{C}_{\mathrm{N}}$ and $\mathrm{C}_{\mathrm{F}}$ were "corrected" for the localization error, it still turned out that $\Delta t_{N}>$ $\Delta \mathrm{t}_{\mathrm{F}}$ for observer F.C. and that $\Delta \mathrm{t}_{\mathrm{N}}<\Delta \mathrm{t}_{\mathrm{F}}$ for observer M. M. , particularly for the displacements produced by the larger differences of binocular retinal illuminance. In all cases, the computed average latencydifference $\overline{\Delta t}$, remained virtually unchanged when the. respective values of $\Delta \mathrm{t}_{\mathrm{N}}$ and $\Delta \mathrm{t}_{\mathrm{F}}$ were each "corrected" for the localization error. 


\section{REFERENCES}

1. Pulfrich, C., "Die Stereoskopie im Dienste der Isochromen und Heterochromen Photometrie," Naturwissenschaften 10: 553-564, 569-574, 596-601, 714-722, $735-743$, and 751-761(1922).

2. Lit, A., "The Magnitude of the Pulfrich Stereophenomenon as a Function of Binocular Differences of Intensity at Various Levels of Illumination, "Amer. J. Psychol. 62: 159-181 (1949).

3. Lit, A., and Hyman, A., "The Magnitude of the Pulfrich Stereophenomenon as a Function of Distance of Observation, "Amer. J. Optom. 28: 564-580 (1951).

4. Engelking, E., and Poos, F., "Ueber die Bedeutung des Stereophänomens für die Isochrome und Heterochrome Helligkeitsvergleichung, "Arch. f. Ophthal. 114: $340-379$ (1924).

5. Banister, H., "Retinal Action Time," in Report of a Joint Discussion on Vision held on June 3, 1932 at the Imperial College of Science by the Physical and Optical Societies, published by the Physical Society of London, pp. 227-235 (1932).

6. Wölfflin, E., "Untersuchungen über den Pulfrichschen Stereoeffekt, "Arch. Augenheilk. 95: 167-179 (1925).

7. Arndt, G., "Ueber die Abhängigkeit des Stereoeffektes von der Geschwindigkeit der Bewegten Marke," Z. Biol. 90: 574-588 (1930).

8. Holz, J., "Der Stereoeffekt Pulfrichs und die Empfindungszeit, "Z. Biol. 95: $502-516$ (1934).

9. Liang, T., and Piéron, H., "Recherches sur la Latence de la Sensation Lumineuse par la Méthode de l'Effect Chronostéréoscopique," Année Psychol. 43-44 : $1-53$ (1947).

10. Frohlich, F. W., "Über die Abhängigkeit der Empfindungszeit und des zeitlichen Verlaufes der Gesichtsempfindung von der Intensität, Dauer und Geschwindigkeit der Belichtung, " Z. Sinnesphysiol. 55: 1-46 (1923). 



\section{DISTRIBUTION LIST 3, PROJECT MICHIGAN REPORTS 1 February 1959 - Effective Date}

\section{Copy No. Addressee}

1

2 25, D. C.
Director, Weapons Systems Evaluation Group, Room 1E880, The Pentagon, Washington 25, D. C.

Office, Assistant Secretary of Defense (R and E), Technical Library, Department of Defense, Washington

Office, Deputy Chief of Staff for Military Operations, Director, Organization and Training, Doctrines and Combat Developments Division, Department of the Army, Washington 25, D. C.

Office, Assistant Chief of Staff for Intelligence, Department of the Army, Washington 25, D. C. ATTN: Chief, Combat Developments/G-2 Air Branch

Chief of Engineers, Department of the Army, Washington $25, \mathrm{D}$. C.

ATTN: ENGNF

Chief of Engineers, Department of the Army, Washington $25, \mathrm{D}$. C.

ATTN: ENGIS

Office, Chief of Research and Development, Department of the Army, Washington 25, D. C.

ATTN: Army Research Office

Office, Chief of Research and Development, Department of the Army, Washington 25, D. C.

ATTN: Chief, Communications - Electronics Division

Chief, Research and Development Division, Office of the Chief Signal Officer, Department of the Army, Washington $25, \mathrm{D}$. C.

Office, Chief of Ordnance, Research and Development Division, Department of the Army, Washington 25, D. C. ATTN: ORDTB, Research and Special Projects

Commanding Officer, Army Map Service, Corps of Engineers, U. S. Army, Washington 25, D. C.

ATTN: Document Library

Chief, U. S. Army Security Agency, Arlington Hall Station, Arlington 12, Virginia

ATTN: GAS-24L

U. S. Army Combat Surveillance Agency, $1124 \mathrm{~N}$. Highland Street, Arlington 1, Virginia

Commander, Army Rocket and Guided Missile Agency, Redstone Arsenal, Alabama

ATTN: Technical Library ORDXR-OTL

Ordnance Tank Automotive Command, Detroit Arsenal, Centerline, Michigan

ATTN: ORDMC-RP

Commanding General, U. S. Continental Army Command, Fort Monroe, Virginia

ATTN: ATSWD-G

Chief, U. S. Army Ordnance District, Los Angeles, 55 South Grand Avenue, Pasadena, California

ATTN: ORDEV-OO

\section{Copy No. Addressee}

26 Chief, U. S. Army Armor Human Research Unit, Fort Knox, Kentucky

ATTN: Task ARMORNITE

27-28 Director, U. S. Army Snow Ice and Permafrost Research Establishment, CE, 1215 Washington Avenue, Wilmette, Illinois

ATTN: Coordination and Publications Branch

Director, U. S. Army Engineer Research and Development Laboratories, Fort Belvoir, Virginia

ATTN: Chief, Topographic Engineering Department

30 Director, U. S. Army Engineer Research and Development Laboratories, Fort Belvoir, Virginia ATTN: Chief, Electrical Engineering Department

31 Director, U. S. Army Engineer Research and Development Laboratories, Fort Belvoir, Virginia

32-47 Commanding Officer, U. S. Army Signal Research and Development Laboratory, Fort Monmouth, New Jersey ATTN: SIGFM/EL-REA

Director, U. S. Army Engineer Waterways Experiment Station, P. O. Box 631, Vicksburg, Mississippi

ATTN: Research Center Library

49 Commanding General, U. S. Army Electronic Proving Ground, Fort Huachuca, Arizona

ATTN: Technical Library

Commandant, U. S. Army Aviation School, Fort Rucker, Alabama

Commandant, U. S. Army Armor School, Fort Knox, Kentucky

ATTN: Combat Developments Group

52 Assistant Commandant, U. S. Army Engineer School, Fort Belvoir, Virginia

ATTN: Combat Developments Group

53-54 Commandant, U. S. Army Signal School, Fort Monmouti, New Jersey

ATTN: SIGFM/SC-DO

55-56 Assistant Commandant, U. S. Army Artillery and Missile School, Fort Sill, Oklahoma

57-61 Assistant Commandant, U. S. Army AAA and GM School, Fort Bliss, Texas

62 Commandant, U. S. Army Command and General Staff College, Fort Leavenworth, Kansas

ATTN: Archives

63 Commandant, U. S. Army Infantry School, Fort Benning, Georgia

ATTN: Combat Developments Office

64 President, U. S. Army Armor Board, Fort Knox, Kentucky

65-66 President, Army Intelligence Board, U. S. Army Intelligence Center, Fort Holabird, Maryland 


\section{DISTRIBUTION LIST $3 \quad 1$ February 1959 - Effective Date}

\section{Copy No. Addressee}

67 President, U. S. Army Airborne and Electronics Board, Fort Bragg, North Carolina

68

President, U. S. Army Signal Board, Fort Monmouth, New Jersey

69

President, U. S. Army Aviation Board, Fort Rucker, Alabama

President, U. S. Army Infantry Board, Fort Benning Georgia

President, U. S. Army Air Defense Board, Fort Bliss, Texas

President, U. S. Army Artillery Board, Fort Sill, Oklahoma

Commanding Officer, U. S. Army Signal Electronic Research Unit, Post Office Box 205, Mountain View, California

Chief, Office of Naval Research, Building T-3, Department of the Navy, Washington 25, D. C.

ATTN: Code 900

Office of Naval Research (Code 463), Department of the Navy, 17th and Constitution Avenue, N. W., Washington $25, \mathrm{D}$. C.

Chief, Bureau of Ships, Department of the Navy, Washington $25, \mathrm{D}$. C.

ATTN: Code $687 \mathrm{C}$

BUSHIPS Technical Library, Code 312, Department of the Navy, Washington 25, D. C.

Director, U. S. Naval Research Laboratory, Washington $25, \mathrm{D}$. C.

AITN: Code 2027

Commanding Officer, U. S. Navy Ordnance Laboratory, Corona, California

ATTN: Library

Commanding Officer and Director, U. S. Navy Electronics Laboratory, San Diego 52, California

ATTN: Library

Commanding Officer and Director, U. S. Naval Training Device Center, Port Washington, New York

ATTN: Librarian

Department of the Air Force, Headquarters, USAF, ACS/Intelligence, Washington 25, D. C.

ATTN: AFCIN-3A1e

Department of the Air Force, Headquarters, USAF, Washington 25, D. C.

ATTN: AFOIN-1B1

Department of the Air Force, Washington 25, D. C.

ATTN: Directorate of Requirements

Department of the Air Force, Headquarters, USAF, Washington $25, \mathrm{D}$. C.

ATTN: AFDRD
Copy No. Addressee

97 Air Research and Development Command, Andrews Air Force Base, Washington 25, D. C.

ATTN: RDZEO

98 Headquarters, Tactical Air Command, Langley Air Force Base, Hampton, Virginia

ATTN: TOOT - Michigan Project Officer

99 Headquarters, Tactical Air Command, Langley Air Force Base, Hampton, Virginia

ATTN: TOOA - Michigan Project Officer

100 Commander, Air Technical Intelligence Center, Wright-Patterson Air Force Base, Ohio

ATTN: AFCIN-4A1C

101 Commander, U. S. Air Force Security Service, San Antonio, Texas

ATTN: CLR

102 Commander, Aeronautical Chart and Information Center Air Photographic and Charting Service (MATS), Second and Arsenal Streets, St. Louis 18, Missouri

ATTN: ACOC

103-112 Commander, Armed Services Technical Information Agency, Arlington Hall Station, Arlington 12, Virginia ATTN: TIPDR

113 Commander-in-Chief, Pacific Air Force, APO 953, c/o Postmaster, San Francisco, California

ATTN: Operations Analysis Office

Commander, Rome Air Development Center, Griffiss Air Force Base, New York

ATTN: RCSSLD

Commander, Wright Air Development Center, Wright-Patterson Air Force Base, Ohio

ATTN: WCOL-9

116 Commander, Wright Air Development Center, Wright-Patterson Air Force Base, Ohio

ATTN: WCLOR

117-122 Commander, Wright Air Development Center, Wright-Patterson Air Force Base, Ohio

ATTN: WCLRS

Commander, Air Proving Ground Center, Eglin Air Force Base, Florida

ATTN: Technical Library

Commandant, USAF Air Ground Operations School, Keesler Air Force Base, Mississippi

125-126 Commandant, School of Aviation Medicine, USAF, Randolph Air Force Base, Texas

ATTN: Research Secretariat

127-128 Commandant of the Marine Corps (Code A02), Headquarters, U. S. Marine Corps, Washington 25, D. C.

129 Commandant of the Marine Corps (A04E), Headquarters, U. S. Marine Corps, Washington 25, D. C. 


\author{
DISTRIBUTION LIST $3 \quad 1$ February 1959 - Effective Date \\ Copy No. Addressee \\ 130 Director, Marine Corps Landing Force Development \\ Center, Marine Corps School, Quantico, Virginia \\ 131-134 Central Intelligence Agency, 2430 E. Street, N. W., \\ Washington 25, D. C. \\ ATTN: OCR Mail Room \\ 135-136 Combat Surveillance Project, Cornell Aeronautics \\ Laboratories, Box 168, Arlington 10, Virginia \\ ATTN: Technical Library \\ 137-138 Light Military Electronic Equipment, Technical Library, \\ General Electric Company, French Road Plant, Utica, \\ New York \\ VIA: Air Force Plant Office, No. 104, General Electric \\ Company, French Road Plant, Utica, New York \\ 139 Operations Research Incorporated, 8605 Cameron \\ Street, Silver Spring, Maryland \\ 140-144 National Advisory Committee for Aeronautics, \\ 1512 H. Street, N. W. Washington 25, D. C. \\ ATTN: Library \\ Motorola, Inc., Riverside Research Laboratory, \\ 8330 Indiana, Riverside, California \\ ATTN: Librarian \\ 146 The RAND Corporation, 1700 Main Street, Santa Monica, \\ California \\ ATTN: Library \\ 147 The Martin Company, Baltimore 3, Maryland \\ ATTN: Engineering Library \\ VIA: Air Force Plant Representative, WRAMA, The \\ Martin Company, Baltimore 3, Maryland \\ 148-149 Hughes Aircraft Company, Culver City, California \\ ATTN: Technical Library, Documents Group \\ VIA: Air Force Plant Representative, Hughes Aircraft \\ Company, Culver City, California \\ Copy No. Addressee \\ 156 Cornell Aeronautical Laboratory, Inc., 4455 Genesee \\ Street, Buffalo 21, New York \\ ATTN: Librarian \\ VIA: Bureau of Aeronautics Representative, 4455 Genesee \\ Street, Buffalo 21, New York \\ 157-158 Visibility Laboratory, Scripps Institution of Oceanography, \\ University of California, San Diego 52, California \\ 159-160 Stanford Research Institute, Engineering Division, \\ Menlo Park, California \\ ATTN: Document Center \\ 161-162 Control Systems Laboratory, University of Illinois, \\ Urbana, Illinois \\ ATTN: Librarian \\ 163 \\ Commanding General, U. S. Army Combat Development \\ Experimental Center, Fort Ord, California \\ 164 Member, Chief Signal Officer's Technical Advisory \\ Committee (Dr. W. R. G. Baker), c/o Syracuse \\ University Research Corporation, P. O. Box 26, \\ University Station, Syracuse 10, New York \\ Aeronutronic Systems, Inc., Library, 1234 Air Way, \\ Glendale, California \\ VIA: Commanding General, U. S. Army Signal Research \\ and Development Laboratory, Fort Monmouth, \\ New Jersey \\ ATTN: SIGFM/EL-NED \\ 166-167 Director, Human Resources Research Office, The George \\ Washington University, P. O. Box 3596, Washington 7, \\ D. C. \\ ATTN: Library \\ Commander, Air Force Cambridge Center, (ARDC), \\ Laurence G. Hanscomb Field, Bedford, Massachusetts \\ ATTN: CROTLS \\ 150 Barnes Engineering Company, 30 Commerce Road, \\ Stamford, Connecticut \\ ATTN: Technical Librarian, Infrared Division \\ VIA: Inspector of Naval Materiel, 181 Middle Street, \\ Bridgeport, Connecticut \\ 151 Deputy Director of Research and Development, Office \\ of the Secretary, Department of the Army, Washington \\ 25, D. C. \\ 152 Member, Chief Signal Officer's Technical Committee \\ (Dr. Michael Ference, Jr.), c/o Ford Motor Company, \\ P. O. Box 2053, Dearborn, Michigan \\ 153 Operations Research Office, The Johns Hopkins \\ University, 6935 Arlington Road, Bethesda, Maryland, \\ Washington $14, \mathrm{D}$. C. \\ ATTN: Chief, Intelligence Division \\ 154-155 Columbia University, Electronics Research Laboratories, \\ 632 W. 125th Street, New York 27, New York \\ ATTN: Technical Library \\ VIA: Commander, Rome Air Development Center, \\ Griffiss Air Force Base, New York \\ Director of Research, U. S. Army Infantry Human \\ Research Unit, P. O. Box 2086, Fort Benning, Georgia \\ ATTN: Library \\ 170-171 Commander-in-Chief, U. S. Air Force Europe, APO 633, \\ New York, New York \\ ATTN: ATI Directorate DCS/Intell \\ HumRRO ARMAV Division, P. O. Box 428 , \\ Fort Rucker, Alabama \\ ATTN: Library \\ U. S. Continental Army Command Liaison Officer, \\ Project MICHIGAN Willow Run Laboratories, \\ Ypsilanti, Michigan \\ Corps of Engineers Liaison Officer, Project \\ MICHIGAN Willow Run Laboratories. \\ Ypsilanti, Michigan \\ ATTN: RCSSTL-L \\ Commanding Officer, U. S. Army Liaisun Group, \\ Project MICHIGAN Willow Run Laboratories, \\ Ypsilanti, Michigan
}






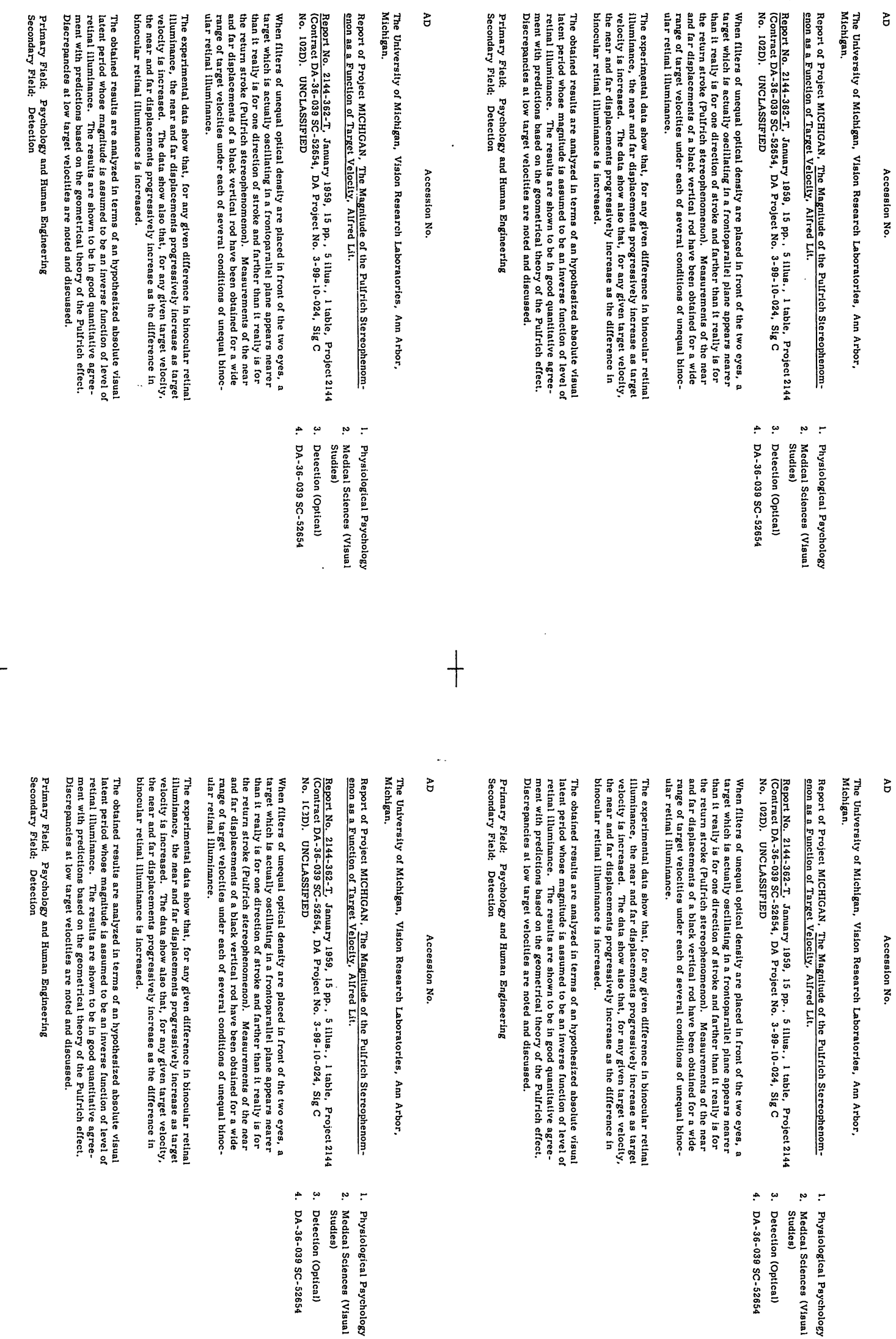
UNIVERSITY OF MICHIGAN

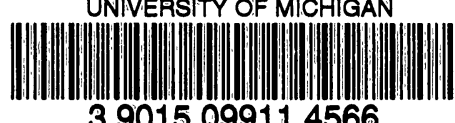

З 9015099114566 




\section{AIIM SCANNER TEST CHART \# 2}

Spectra

ABCDEFGHIJKLMNOPQRSTUVWXYZabcdefghijklmnopqrstuvwxyz;:',./?\$0123456789

10 PT ABCDEFGHIJKLMNOPQRSTUVWXYZabcdefghijkImnopqrstuvwxyz;:'“,./?\$0123456789

Times Roman

4 PT ABCDEFGHIJKLMNOPQRSTUVWXYZabcdefghijklmnopqrstuwwxyz:." $/ 25012345678$

6 PT ABCDEFGHIJKLMNOPQRSTUVWXYZabcdefghijklmnopqrstuvwxyz;:“,./?\$0123456789

8 PT ABCDEFGHIJKLMNOPQRSTUVWXYZabcdefghijklmnopqrstuvwxyz;:“,./?\$0123456789

10 PT ABCDEFGHIJKLMNOPQRSTUVWXYZabcdefghijklmnopqrstuvwxyz;:’,,./?\$0123456789

Century Schoolbook Bold

4 PT $\quad$ ABCDEFGHIJKLMNOPQRSTUVWXYZabcdefghijklmnopqrstuvwxyz;" ", $/$ ?s0123456789

6 PT ABCDEFGHIJKLMNOPQRSTUVWXYZabcdefghijklmnopqrstuvwxyz;:",,,/?\$0123456789

8 PT ABCDEFGHIJKLMNOPQRSTUVWXYZabcdefghijklmnopqrstuvwxyz;:",.//\$0123456789

10 PT ABCDEFGHIJKLMNOPQRSTUVWXYZabcdefghijklmnopqrstuvwxyz;:",../?012\$456789

\section{News Gothic Bold Reversed}

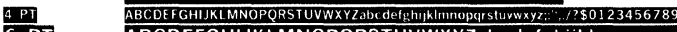

6 PT ABCDEFGHIJKLMNOPQRSTUVWXYZZabcdefghijkimnopqrstuvwXyz::",./? \$0123456789

8 PT ABCDEFGHIJKLMNOPQRSTUVWXYZabcdefghijklmnopqrsturwxyz;;",./?\$0123456789

10 PT ABCDEFGHIJKLMNOPQRSTUVWXYZabcdefghijklmnopqrstuvwxyz;:" ,./?\$0123456789

\section{Bodoni Italic}

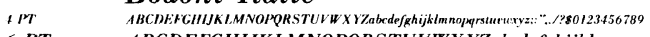

6 PT ABCDEFGHIJKLMNOPQRSTUVWXYZabcdefghijklmnopqrstuvwxyz;:"./?\$0123456789

8 PT ABCDEFGHIJKLMNOPQRSTUVWXYZabcdefghijklmnopqrstuvwxyz;:",./?\$0123456789

10 PT ABCDEFGHIJKLMNOPQRSTUVWXYZabcdefghijklmnopqrstuvwxyz;:”,./?\$01/23456789

Greek and Math Symbols

6 PT

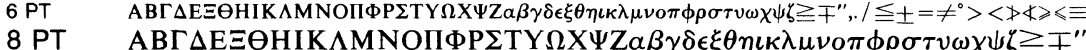

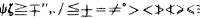

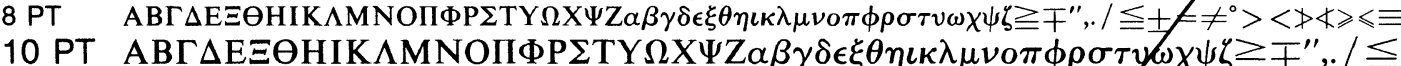

АВГ $\Delta \mathrm{E} \Xi \Theta H I K \Lambda$ МNOПФР

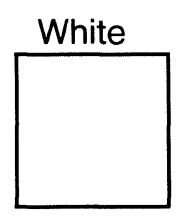

Black

MESH HALFTONE WEDGES

65

85

100

110

133

150
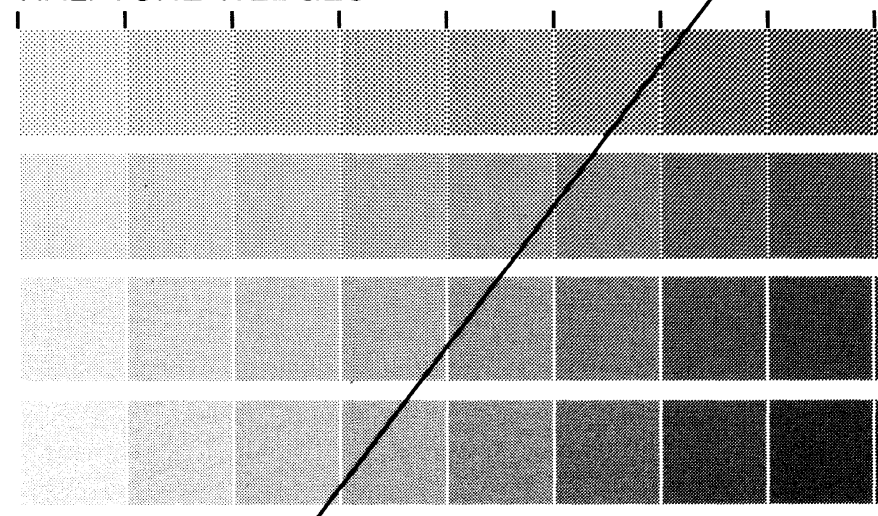

Isolated Characters

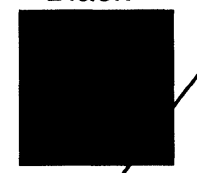

A4 Page 6543210
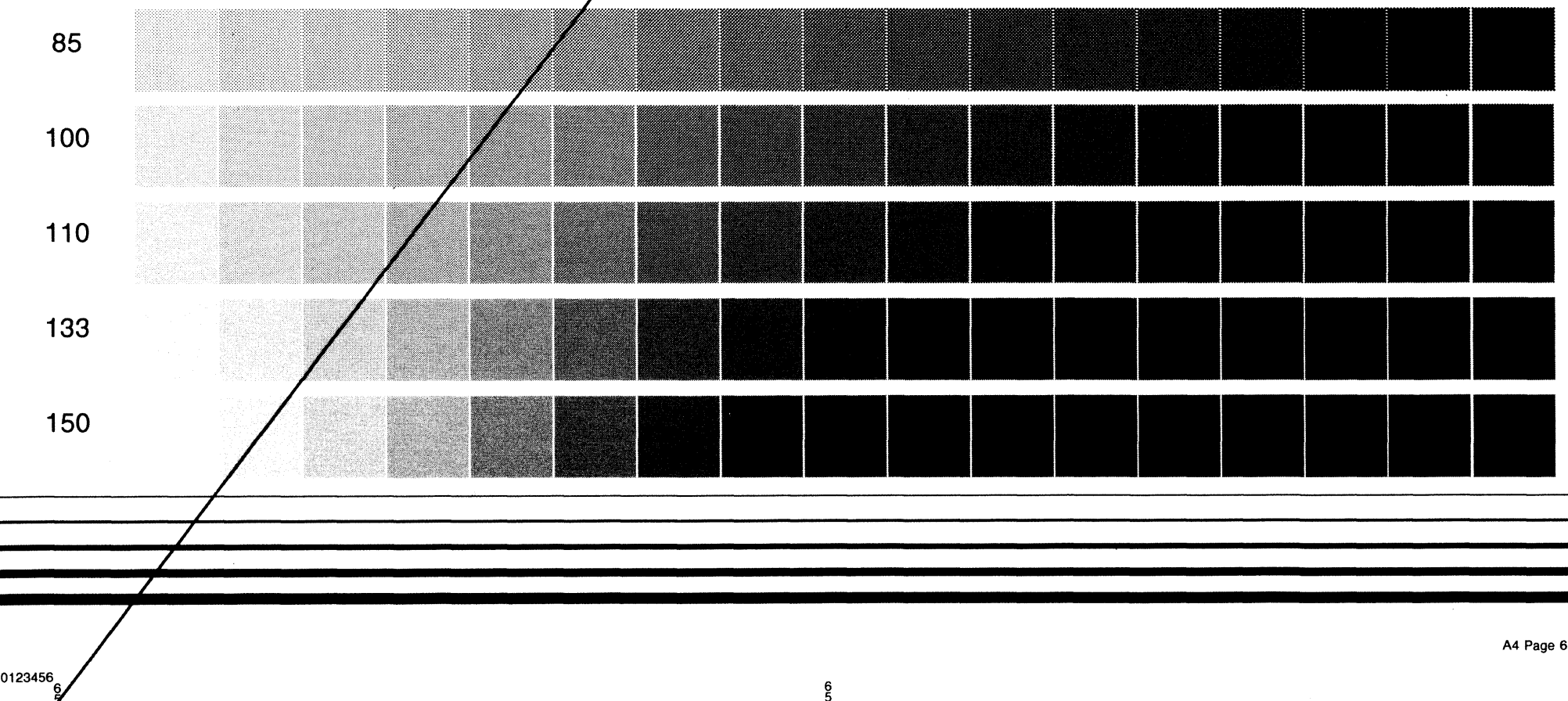
RIT ALPHANUMERIC RESOLUTION TEST OBJECT, RT-1-71

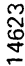

$x$

r

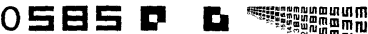
1 르

宸

2 듴

3 ㅋㄹㅌ

4 릌

5 5ㅂㄹ

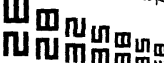

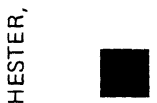

6 E酒 7

IIImunim

100

O- NMVLO

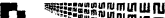
$\rightarrow=$ 政

山m $\omega_{\mathbf{m}_{\mathrm{m}}}$

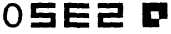
1 ㅌㄷ

2 로

$\stackrel{4}{\check{x}}$ 3 트르 IIIU⿴囗十⺝⿱⺈⿻コ一心 4 로

5 5Eㄹ

6 的 85

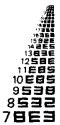

$\frac{1}{\frac{1}{0}}$

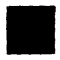

